\title{
THE EFFECT OF INCREASED CU CONTENT ON MICROSTRUCTURE AND MELTING OF UTILIZED SN-0.3AG-0.7CU SOLDER
}

\author{
Marián DRIENOVSKÝ ${ }^{1 *}$, Lýdia RÍZEKOVÁ TRNKOVÁ ${ }^{1}$, Roman ČIČKKA ${ }^{1}$, \\ Pavol PRIPUTEN $^{1}$, Marcela PEKARČÍKOVÁ ${ }^{1}$, Jozef JANOVEC ${ }^{2}$ \\ ${ }^{1}$ SLOVAK UNIVERSITY OF TECHNOLOGY IN BRATISLAVA, \\ FACULTY OF MATERIALS SCIENCE AND TECHNOLOGY IN TRNAVA, \\ INSTITUTE OF MATERIALS SCIENCE, \\ ULICA JÁNA BOTTU 2781/25, 91724 TRNAVA, \\ ${ }^{2}$ SLOVAK UNIVERSITY OF TECHNOLOGY IN BRATISLAVA, UNIVERSITY SCIENCE PARK, \\ VAZOVOVA 5, 81243 BRATISLAVA, SLOVAK REPUBLIC \\ e-mail: marian.drienovsky@stuba.sk, lydia.trnkova@stuba.sk, roman.cicka@stuba.sk, \\ pavol.priputen@stuba.sk, marcela.pekarcikova@stuba.sk,jozef.janovec@stuba.sk \\ *corresponding author \\ Received: 29.10.2018, Accepted: 09.01.2019, Published: 29.01.2019
}

\begin{abstract}
The influence of increased $\mathrm{Cu}$ and Ag contents on the microstructure evolution in the utilized Sn-0.3Ag-0.7Cu (wt. \%) solder was studied. The utilized solder was exploited in the wave soldering process at the temperatures of about $260{ }^{\circ} \mathrm{C}$ for several days. The samples investigation involved the differential scanning calorimetry, the scanning electron microscopy including the energy dispersive X-ray spectroscopy, and the X-ray diffraction techniques. To predict phase equilibria at various temperatures and temperature dependences of heat capacity, the Thermo-Calc software and the COST531 lead-free solder database were used. The original and the utilized solders were found to be very similar regarding the phase occurrence, but slightly differ from one another in microstructure evolution due to higher bulk contents of $\mathrm{Cu}$ in the latter solder. The obtained results contribute to both the better understanding of the microstructure evolution in low-silver Sn-Ag-Cu solders and the determination of compositional limits for those solders used in the wave soldering process.
\end{abstract}

\section{Key words}

Low-silver Sn-Ag-Cu solder, intermetallic compound, solidification, thermodynamic calculations 


\section{INTRODUCTION}

Tin-base lead-free solders, e.g. eutectic and/or near-eutectic $\mathrm{Sn}-\mathrm{Ag}-\mathrm{Cu}(\mathrm{SAC}), \mathrm{Sn}-\mathrm{Ag}$, and $\mathrm{Sn}-\mathrm{Cu}$ alloys, were used to replace restricted lead-containing solders in microelectronic packaging applications $(1,2)$. Besides the $\beta$-Sn solid solution, they were found to contain intermetallic compounds of (IMC) $\mathrm{Ag}_{3} \mathrm{Sn}$ and $\mathrm{Cu}_{6} \mathrm{Sn}_{5}$ formed on ageing mostly. Seo et al. (3) reported that the kinetics growth of $\mathrm{Ag}_{3} \mathrm{Sn}$ on the ageing of SAC solders is much slower than that of $\mathrm{Cu}_{6} \mathrm{Sn}_{5}$ in $\mathrm{Sn}$-Cu solders. However, $\mathrm{Ag}_{3} \mathrm{Sn}$ shows better stability during high-temperature ageing than $\mathrm{Cu}_{6} \mathrm{Sn}_{5}$. Slowly cooled high-silver SAC solders exhibit mostly a higher hardness, a coarser microstructure containing large primary particles of $\mathrm{Ag}_{3} \mathrm{Sn}$, a lower ductility $(5,6)$, a narrower melting range, and a lower volume fraction of $\beta$-Sn in comparison with the low-silver SAC solders (3-6). Kanlayasiri and Ariga (7) reported that $\beta-\mathrm{Sn}$ is the dominant microstructure constituent in the $\mathrm{Sn}-0.3 \mathrm{Ag}-0.7 \mathrm{Cu}$ solder. The soldering temperature of the solder ranges between 250 and $290{ }^{\circ} \mathrm{C}$ and the solidification range is wider than $10^{\circ} \mathrm{C}(8,9)$.

Ternary phase diagrams and their isoplethal or isothermal sections provide useful tools for the characterisation of phase evolution. Moon et al. (10) and Ohnuma et al. (11) proposed the $\mathrm{Sn}-\mathrm{Ag}-\mathrm{Cu}$ phase diagram via optimizing the experimental data obtained for ternary alloys and the extrapolating of thermodynamic data achieved for the corresponding binaries. For the neareutectic $\mathrm{Sn}-3.5 \mathrm{Ag}-0.9 \mathrm{Cu}$ (wt. \%) solder, they suggested primary $\mathrm{Ag}_{3} \mathrm{Sn}, \mathrm{Cu}_{6} \mathrm{Sn}_{5}, \beta-\mathrm{Sn}$, monovariant $\mathrm{Ag}_{3} \mathrm{Sn}+\beta$-Sn, monovariant $\mathrm{Cu}_{6} \mathrm{Sn}_{5}+\beta-\mathrm{Sn}$, monovariant $\mathrm{Ag}_{3} \mathrm{Sn}+\mathrm{Cu}_{6} \mathrm{Sn}_{5}$ and eutectic $\beta-\mathrm{Sn}+\mathrm{Ag}_{3} \mathrm{Sn}+\mathrm{Cu}_{6} \mathrm{Sn}_{5}$ as possible microstructure constituents and/or phase equilibria. This finding is consistent with that reported by Loomans and Fine (12). Sopoušek et al. (13) studied the $\mathrm{Sn}-1.5 \mathrm{Ag}-0.7 \mathrm{Cu}-9.5 \mathrm{In}$ solder using various methods, and found a good agreement between the DSC (differential scanning calorimetry) records and the values of heat capacity calculated by means of Thermo-Calc software and COST 531 database (14) for nearequilibrium phase transitions.

Laurila et al. (15) reported a rapid dissolution of copper from the substrate in molten Snbase solders. Formation of orthorhombic $\mathrm{Cu}_{3} \mathrm{Sn}$ and hexagonal $\mathrm{Cu}_{6} \mathrm{Sn}_{5}$ at the solder/substrate interface was observed (15-19). Solid state transformations in the bulk or at the solder/substrate interface during the solidification can be accompanied with structural changes of $\mathrm{Cu}_{6} \mathrm{Sn}_{5}$. The high-temperature hexagonal modification of this IMC $(\eta)$ can transform into the lowtemperature monoclinic modification ( $\left.\eta^{\prime}\right)$ at about $186^{\circ} \mathrm{C}(20)$. Usually, the high-temperature $\eta$ occurs also at lower temperatures as a metastable phase, because of kinetic constraints (15). Nogita et al. (21) reported that the $\eta \rightarrow \eta$ ' transformation starts at $140^{\circ} \mathrm{C}$ already after 5 minutes of ageing, while at $100{ }^{\circ} \mathrm{C}$ any discernible transformation for time-frame of the experiment was not observed. Chada et al. (22) confirmed a positive correlation between the $\mathrm{Cu}$ enrichment in molten solder and the increase in volume portion of $\eta$. The amount of dissolved $\mathrm{Cu}$ in the molten solder was found to be dependent on reflow conditions, i.e. temperature and time.

Although the effect of increasing amount of $\mathrm{Ag}$ on microstructure and mechanical properties of SAC solders is known (6), a similar study about the effect of $\mathrm{Cu}$ is missing up to now. The aim of the present research is therefore to obtain more relevant information about changes in the microstructure evolution of low-silver SAC solders enriched by $\mathrm{Cu}$.

\section{MATERIALS AND METHODOLOGY OF EXPERIMENT}

Two samples were investigated in the present research. The original $\mathrm{Sn}-0.3 \mathrm{Ag}-0.7 \mathrm{Cu}$ solder (denoted as SAC_O) and the utilized SAC_U solder used in the wave soldering bath and therefore containing higher amounts of $\mathrm{Cu}$ and $\mathrm{Ag}$. In order to prepare specimens for light microscopy (LM), DSC measurement, X-ray diffraction (XRD), and SEM/EDX (scanning 
electron microscopy/energy dispersive X-ray spectroscopy) experiments, both solders were remelted in ceramic crucibles at $270{ }^{\circ} \mathrm{C}$ for $5 \mathrm{~min}$ and subsequently cast on a stainless steel pad.

The samples for LM were prepared by the conventional metallographic method based on the sample cutting, mounting in duracryl resin, grinding on CarbiMet ${ }^{\circledR}$ abrasive papers $(\mathrm{P} 240$, P600, and P1200), and polishing using diamond suspensions $(9 \mu \mathrm{m}, 6 \mu \mathrm{m}, 3 \mu \mathrm{m}$, and $1 \mu \mathrm{m})$. Finally, all specimens were etched in $3 \%$ nital for few seconds or polished with suspension Mastermet ${ }^{\circledR}$ without etching. The DSC experiments were performed using a Perkin-Elmer Diamond DSC 7 calorimeter. The samples were heated from room temperature to $300{ }^{\circ} \mathrm{C}$. The heating rate of the first preliminary measurement was $10^{\circ} \mathrm{C} \cdot \mathrm{min}^{-1}$. Then precise measurements were done at the heating rate of $1{ }^{\circ} \mathrm{C} \cdot \mathrm{min}^{-1}$ (the second and the third runs). The cooling rate of $10{ }^{\circ} \mathrm{C} . \mathrm{min}^{-1}$ was used in all the runs. Mass of the analysed specimens was $5.6 \mathrm{mg}$ (SAC_O) and $5.8 \mathrm{mg}$ (SAC_U). The microstructure characterization was performed using a light microscope Neophot 30. The phase composition was confirmed by a Philips PW 1830 diffractometer with Bragg-Brentano geometry using filtered $\mathrm{Co}_{\mathrm{K} \alpha 1}$ radiation, scattering angle 2 theta ranged between 30 and $115^{\circ}$, step size was $0.05^{\circ}$ and exposure time was 5 s per step. To determine the chemical composition of phases, a JEOL JSM-7600F scanning electron microscope operating at $20 \mathrm{kV}$ equipped with an INCA energy-dispersive X-ray spectrometer was used.

\section{Thermodynamic calculations}

In general, the thermodynamic description of a phase is based on defining its total Gibbs free energy, G:

$$
G=G^{r e f}+G^{i d}+G^{e x}+G^{m a g},
$$

where $G^{r e f}$ is the reference term, $G^{i d}$ is the ideal mixing energy, $G^{e x}$ is the excess mixing energy, and $G^{m a g}$ is the magnetic term. The thermodynamic model of the phase is dependent on structural characteristics. At present, the sublattice model is widely used for the thermodynamic description of phases. The model makes it possible to consider the mixing of defined components at each sublattice and enables also to calculate the particular contributions to the phase Gibbs free energy (1). The calculations of phase equilibria (stable or metastable) are based on the minimization of the Gibbs free energy of the system. Moreover, important thermodynamic quantities (molar fractions of phases, compositions of phases, Gibbs free energy, Helmholtz free energy, enthalpy, entropy, heat capacity, expansion coefficient, ...) can be easily calculated for the system and/or individual phases, usually in dependence on temperature (23).

The Thermo-Calc software (TCW5) and the COST531 lead-free solder database (14) were used in calculations of phase equilibria for the systems corresponding to the investigated solders. In the calculations, three elements ( $\mathrm{Sn}, \mathrm{Ag}$, and $\mathrm{Cu})$ and five phases $\left(\beta-\mathrm{Sn}, \varepsilon-\mathrm{Ag}_{3} \mathrm{Sn}, \eta\right.$ $\mathrm{Cu}_{6} \mathrm{Sn}_{5}, \eta^{\prime}-\mathrm{Cu}_{6} \mathrm{Sn}_{5}$, and liquid) were considered. Specific denotations of phases used in the COST531 lead-free solder database are given in Table 1. In this research, values of heat capacity were calculated in the temperature range $200-250{ }^{\circ} \mathrm{C}$ according to the equation:

$$
C_{p}=\left(\frac{d H}{d T}\right)_{p}
$$


Table 1: The phases considered in thermodynamic calculations and their specific denotations used in the COST531 lead-free solder database

\begin{tabular}{|c|c|c|}
\hline No. & Phase & Specific denotation of phase \\
\hline 1 & $\varepsilon-\mathrm{Ag}_{3} \mathrm{Sn}$ & AGSB_ORTHO \\
\hline 2 & $\beta-\mathrm{Sn}$ & BCT_A5 \\
\hline 3 & $\eta-\mathrm{Cu}_{6} \mathrm{Sn}_{5}$ & CUIN_ETA \\
\hline 4 & $\eta^{\prime}-\mathrm{Cu}_{6} \mathrm{Sn}_{5}$ & CU6SN5_P \\
\hline 5 & liquid & LIQUID \\
\hline
\end{tabular}

\section{RESULTS}

The microstructure of the SAC_O solder consisting of $\beta$-Sn dendrites and the eutectic ( $\beta$ Sn, $\eta, \varepsilon)$ as dominant constituents is illustrated in Fig. 1. A direct contact between the molten solder and the stainless steel pad led to the formation of finer microstructure (Fig. 1a) due to a rapid heat transfer. On the other hand, the slowly cooled solder adjacent to the free surface exhibits coarser microstructure (Fig. 1b) where particles of $\eta$ with the longitudinal morphology are observable inside the $\beta$-Sn areas. The microstructure of the SAC_U solder (Fig. 2) is different from the microstructure of the SAC_O solder. The structure contains higher amounts of both needle-like $\eta$ particles inside the $\beta$-Sn dendrites and the eutectic (Fig. 2b).

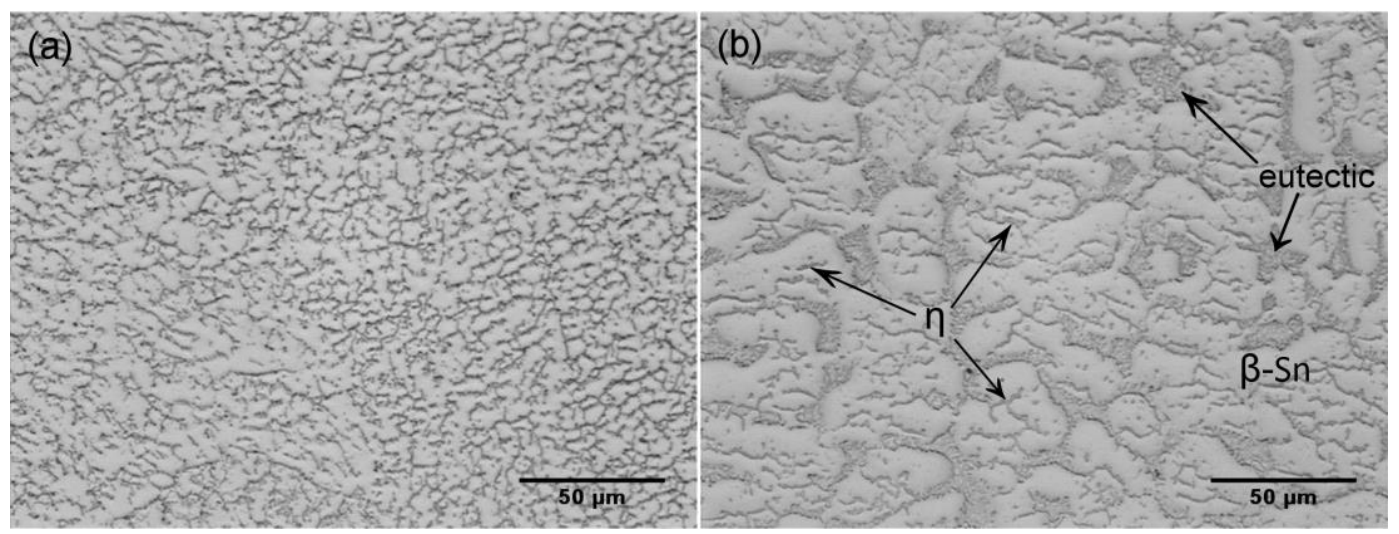

Fig. 1 Fine (a) and coarse (b) microstructures of SAC_O solder of the lower (adjacent to stainless steel pad) and the upper (at free surface) parts of the solidified drop, respectively. The microstructure consists of the $\beta$-Sn areas containing fine $\eta$ particles and the eutectic.
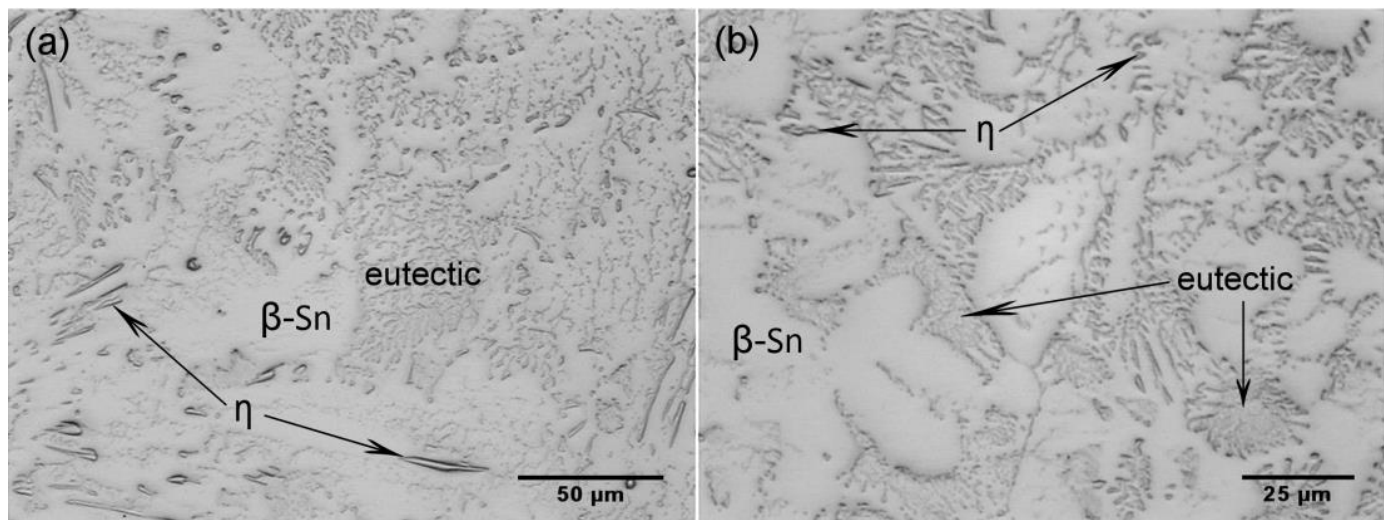

Fig. 2 Microstructure of the SAC_U solder containing longitudinal particles of primary $\eta(a)$ and the eutectic consisting of fine $\eta$ particles and $\beta$-Sn $(b)$ 


\begin{tabular}{|c|c|c|c|}
\hline \multicolumn{3}{|c|}{ Table 2: Metal compositions of investigated samples determined by SEM/EDX } \\
\hline \multirow{2}{*}{ Solder } & \multicolumn{3}{|c|}{ Mass content in $\%$} \\
\cline { 2 - 4 } & $\mathrm{Ag}$ & $\mathrm{Cu}$ & $\mathrm{Sn}$ \\
\hline SAC_O & $0.3 \pm 0.1$ & $0.7 \pm 0.1$ & bal. \\
\hline SAC_U & $0.3 \pm 0.1$ & $0.8 \pm 0.1$ & bal. \\
\hline
\end{tabular}

Metal compositions of the investigated solders determined by the SEM/EDX technique are given in Table 2. At least nine different places were analysed to determine the average metal compositions. The metal composition of the SAC_O solder is very close to the composition declared by the solder manufacturer. In the SAC_U solder, a slightly enhanced concentration of copper was determined. The presence of $\beta-\mathrm{Sn}, \varepsilon-\mathrm{Ag}_{3} \mathrm{Sn}$, and $\eta-\mathrm{Cu}_{6} \mathrm{Sn}_{5}$ was confirmed by XRD in both solders. Diffraction patterns corresponding to the SAC_O and SAC_U solders are illustrated in Figs. 3 and 4, respectively.

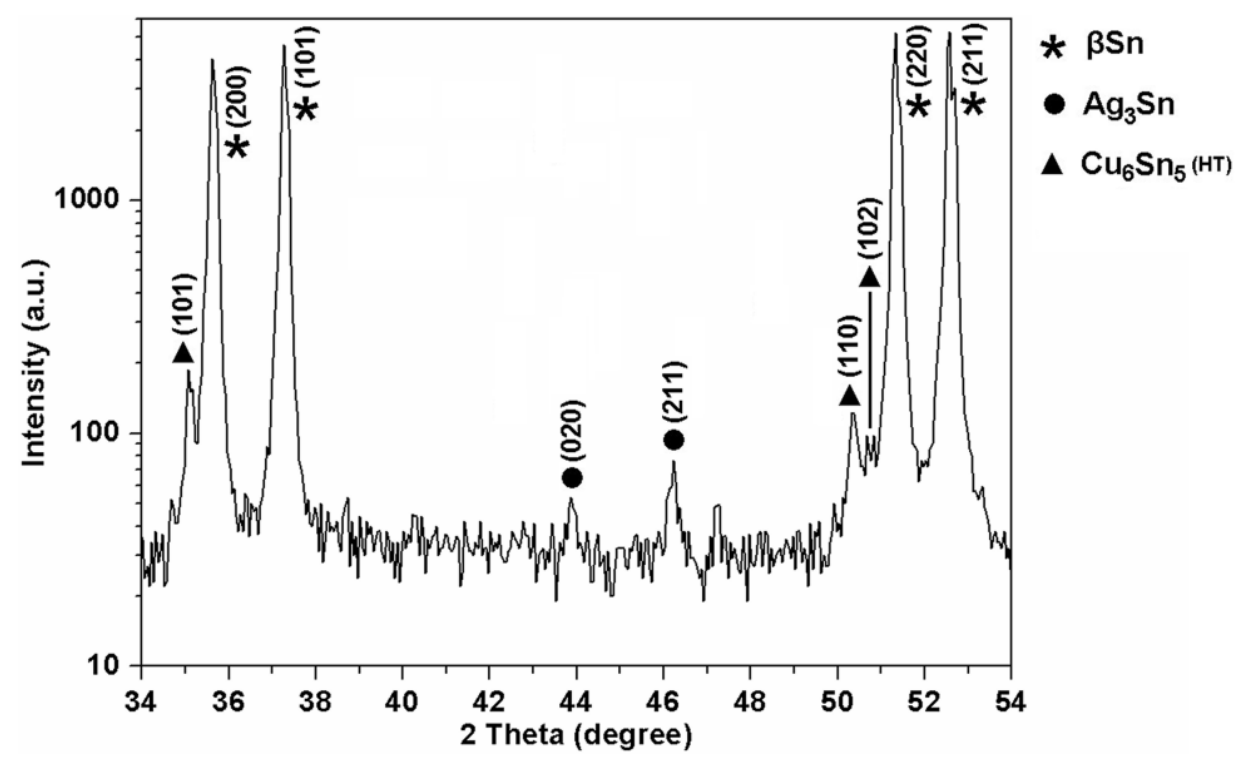

Fig. 3 XRD pattern corresponding to SAC_O solder

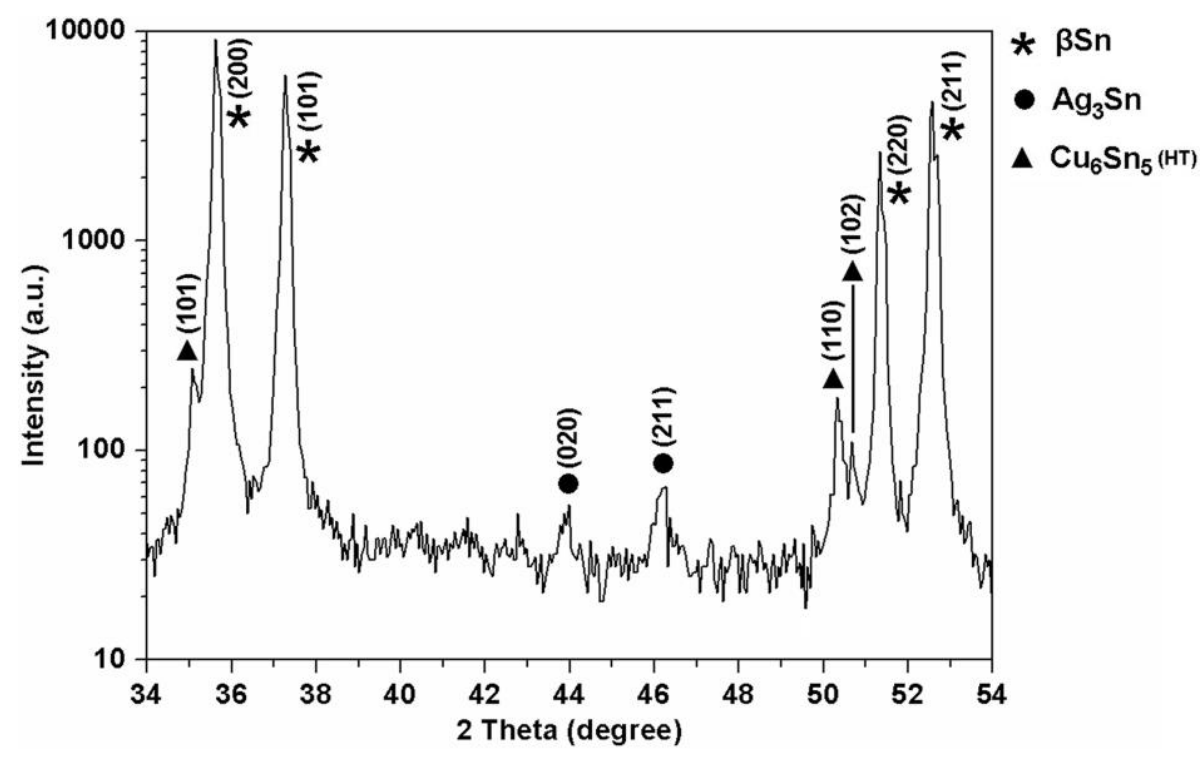

Fig. 4 XRD pattern corresponding to SAC_U solder 
The calculated isoplethal sections of the $\mathrm{Sn}-\mathrm{Ag}-\mathrm{Cu}$ diagram are illustrated in Figs. 5a and 5c for the SAC_O (in the calculation, Ag content of 0.29 wt. \% was considered) and the SAC_U (0.33 wt. \% of Ag) solders, respectively. In Figs. 5b and 5d, details of the diagrams are shown. Variation ranges of the bulk $\mathrm{Cu}$ content determined by the SEM/EDX technique (Table 2) are illustrated in Figs. $5 b$ and $5 d$ in the form of grey bars (see the upper parts of the relevant diagrams). They are also delimited by the thin dashed vertical lines.

(a)

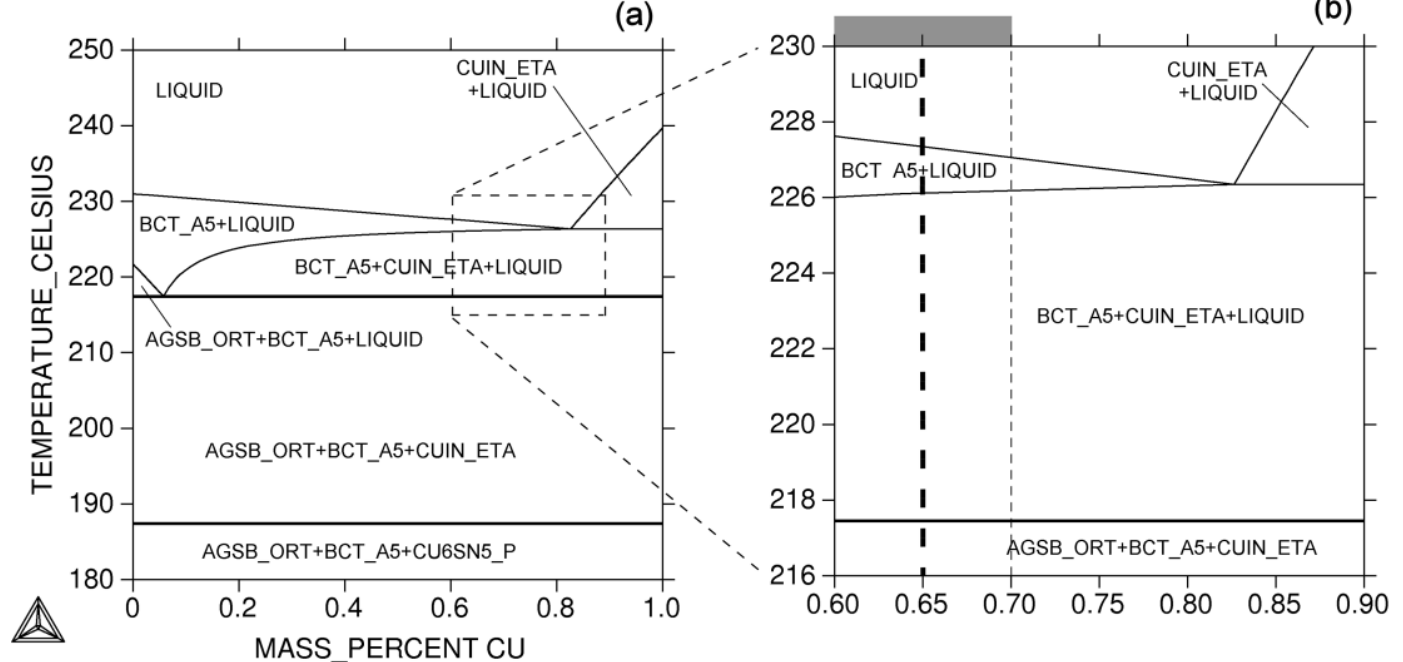

(c)

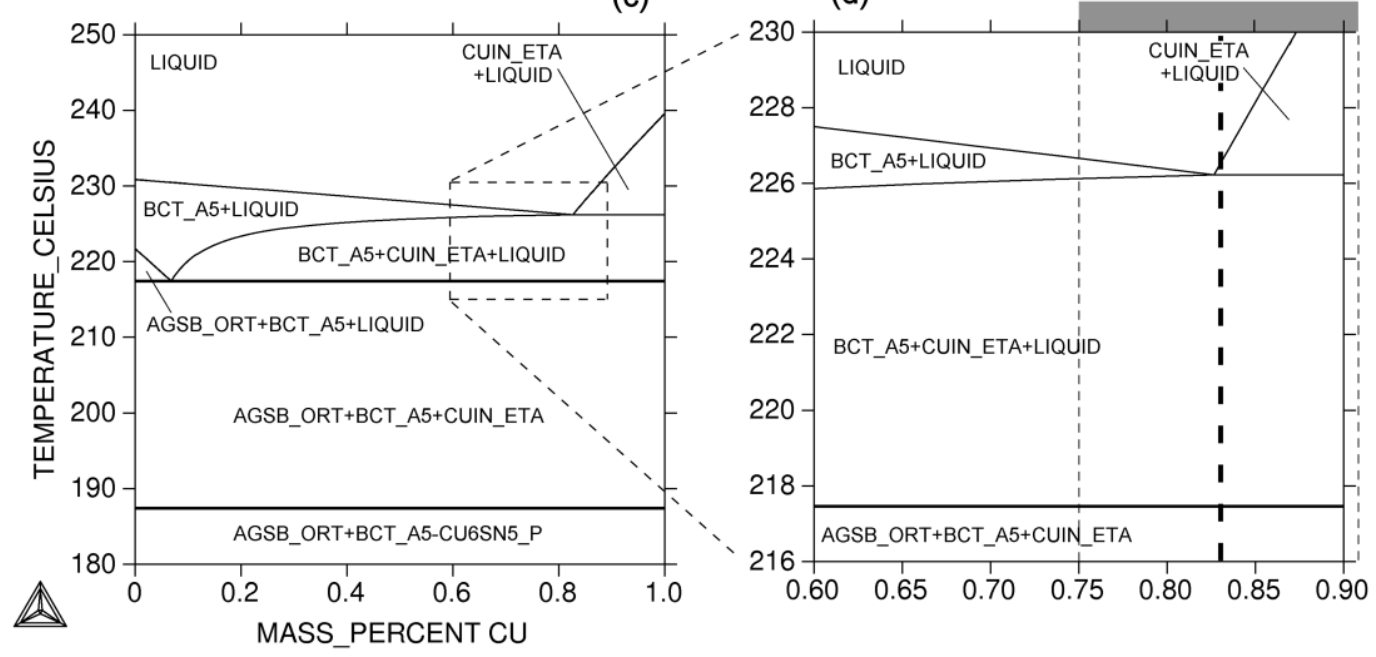

Fig. 5 Calculated tin-rich corners of Sn-Cu isoplethal sections of the Sn-Ag-Cu diagram for $S A C \_O(a, b)$ and $S A C \_U(c, d)$ solders. Estimated composition range of $S A C \_O(b)$ and $S A C \_U(d)$ solders are marked with bold dashed vertical lines. Experimentally determined variation ranges of the bulk $\mathrm{Cu}$ content are marked with grey bars in the diagram upper parts and delimited with thin dashed vertical lines $(b, d)$.

In Figs. 6a and 7a, temperature dependences of the calculated molar heat capacities (Cp) are shown. Three phase transitions associated with changes in the $\mathrm{Cp}$ values were predicted for the SAC_O solder in the temperature range $200-250{ }^{\circ} \mathrm{C}$ :

$$
\left.\begin{array}{c}
\beta-S n+A g 3 S n+\eta \leftrightarrows \beta-S n+\eta+\text { liquid }\left(217.2^{\circ} \mathrm{C}\right) \\
\beta-S n+\eta+\text { liquid } \leftrightarrows \beta-S n+\text { liquid }\left(226.0^{\circ} \mathrm{C}\right) \\
\beta-S n+\text { liquid } \leftrightarrows \text { liquid }\left(227.3^{\circ} \mathrm{C}\right)
\end{array}\right\}
$$


The predicted transitions are valid for both heating and cooling regimes of DSC if done at near-equilibrium conditions. Three phase transitions were also predicted for the SAC_U solder:

$$
\left.\begin{array}{c}
\beta-S n+A g 3 S n+\eta \leftrightarrows \beta-S n+\eta+\text { liquid }\left(217.2^{\circ} \mathrm{C}\right) \\
\beta-S n+\eta+\text { liquid } \leftrightarrows \eta+\text { liquid }\left(226.2^{\circ} \mathrm{C}\right) \\
\eta+\text { liquid } \leftrightarrows \text { liquid }\left(226.5^{\circ} \mathrm{C}\right)
\end{array}\right\}
$$

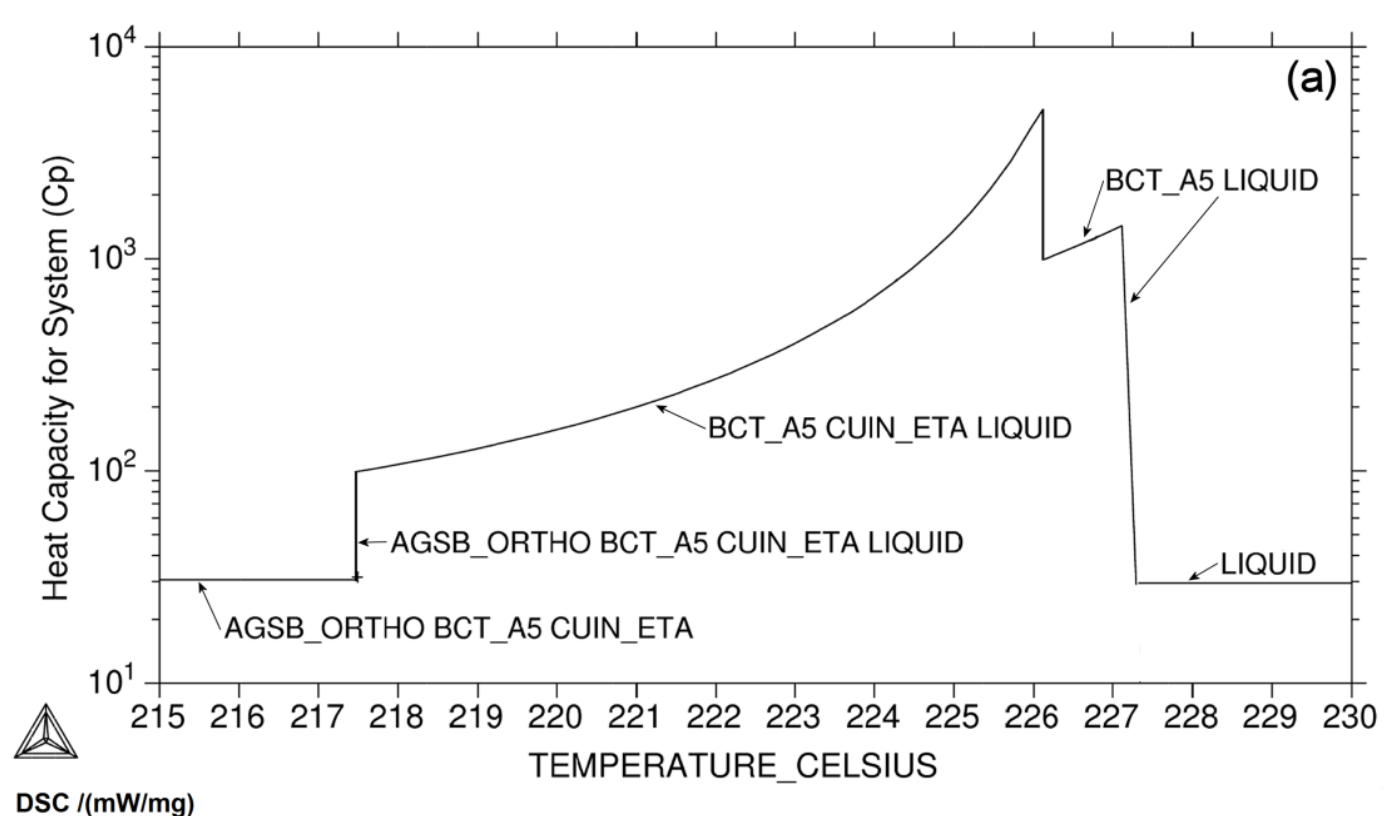

$\mathrm{DSC} /(\mathrm{mW} / \mathrm{mg})$

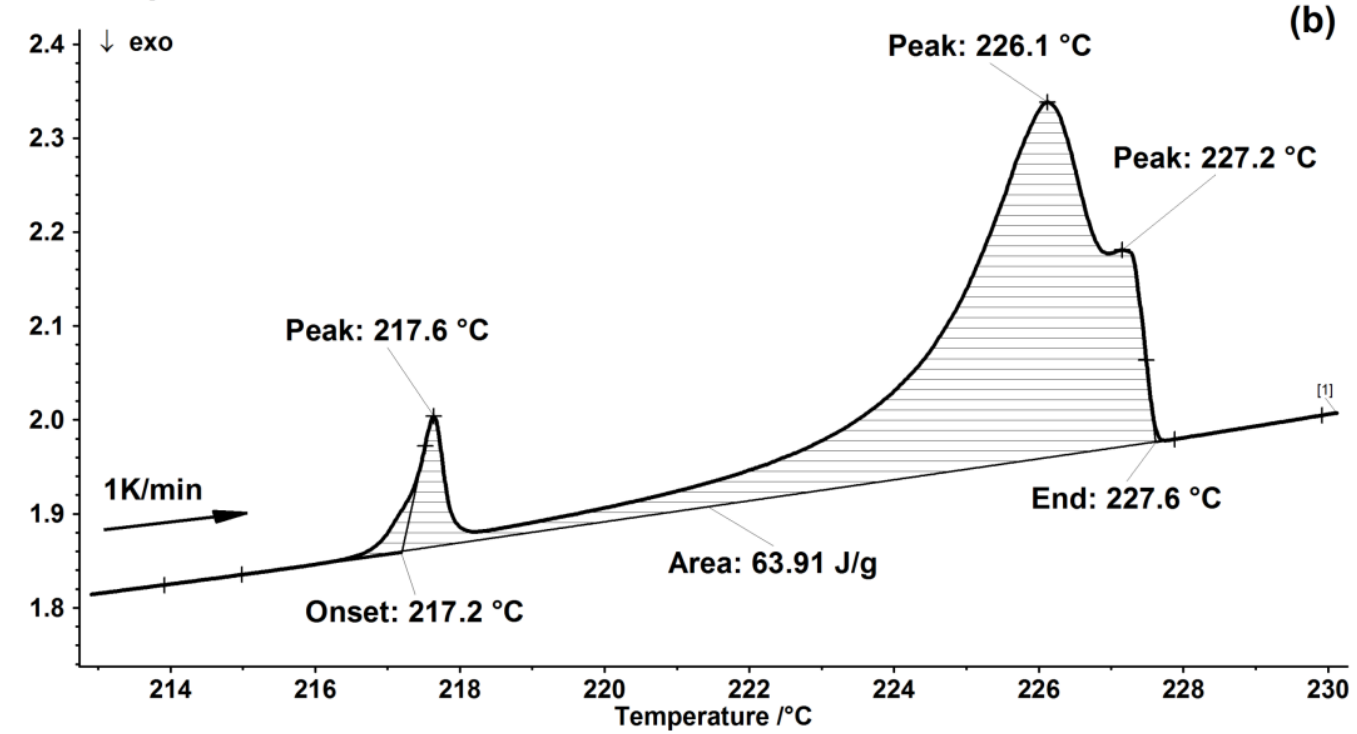

Fig. 6 Temperature dependence of predicted $C p\left(J . K^{-1} . \mathrm{mol}^{-1}\right)$ values with indicated equilibrium phases (a) and the corresponding experimental DSC curve (b) for the SAC_O solder 


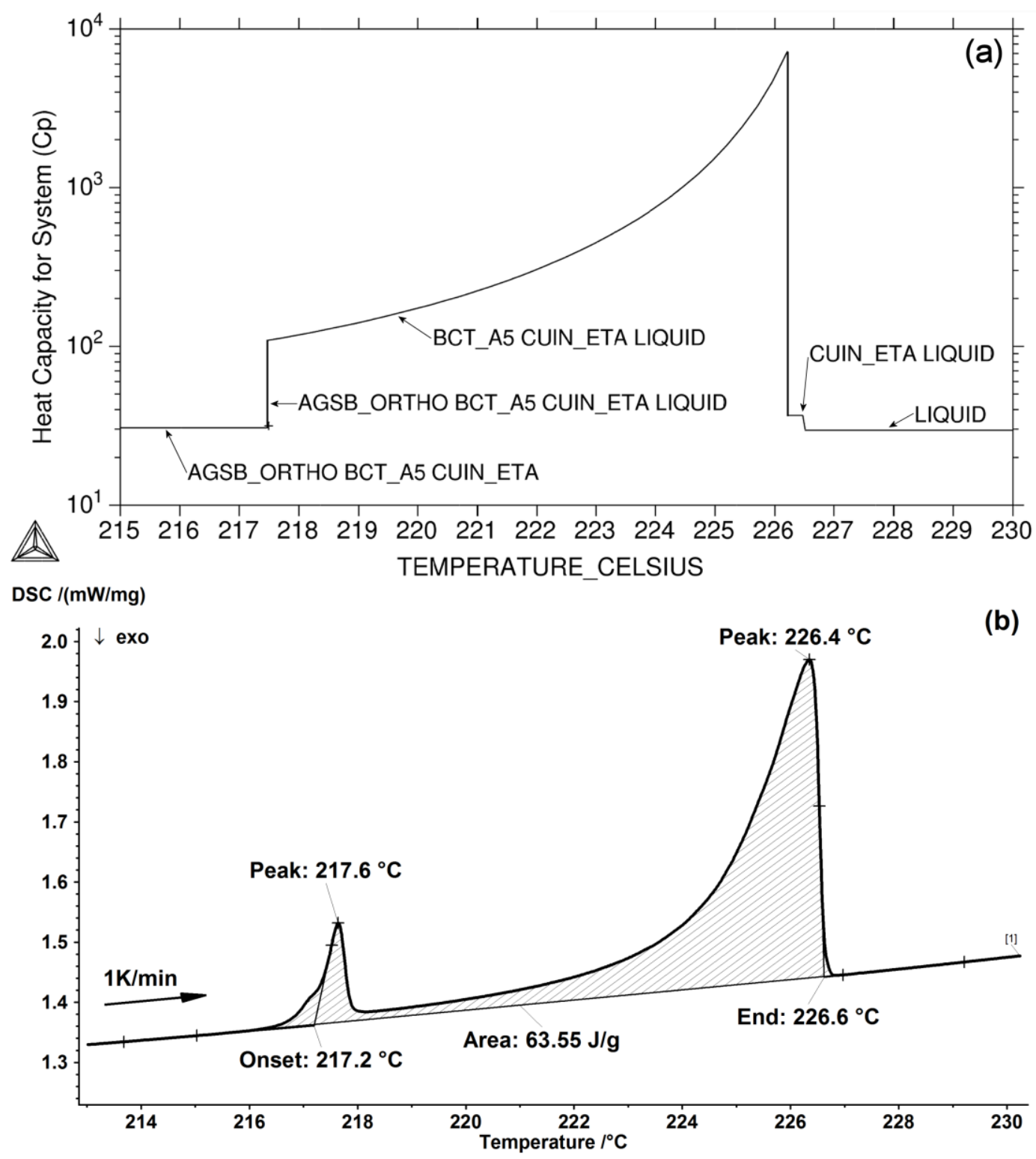

Fig. 7 Temperature dependence of predicted $C p\left(J . K^{-1} . m^{-1}\right)$ values (a) and the corresponding experimental DSC curve (b) for the $S A C_{-} U$ solder

It can be seen that the SAC_O and SAC_U solders differ from one another in the second and the third phase transitions (3), (4). According to the thermodynamic predictions, $\beta$-Sn and $\eta$ should be the finally melted phases in the SAC_O and SAC_U solders, respectively. Experimental DSC curves corresponding to the heating regime are illustrated in Fig. $6 \mathrm{~b}$ for the SAC_O solder and in Fig. 7b for the SAC_U solder.

\section{DISCUSSION ON RESULTS}

The ways of the SAC_O and SAC_U solidification showed some differences influencing also the final microstructures. In the former solder, the solidification process comprised the formation of primary $\beta$-Sn, then $\eta$ by the monovariant reaction, and finally the rest of liquid transformed into $\beta$-Sn $+\varepsilon+\eta$ by eutectic reaction (Fig. 5a). The $\beta$-Sn, $\varepsilon$, and $\eta$ were identified in the solder final microstructure (Figs. 1 and 3) that confirms the finding of Hsiao et al. (18) about the elimination of $\eta \rightarrow \eta^{\prime}$ transformation in some SAC solders. Variations of the $\mathrm{Cu}$ and 
Ag contents (Table 2) were not found to affect the homogeneity of the microstructure consisting of the regularly distributed primary $\beta$-Sn areas and the eutectic. The reason resides in the position of the $\mathrm{Cu}$ variation range in the isoplethal section of the $\mathrm{Sn}-\mathrm{Ag}-\mathrm{Cu}$ phase diagram (Fig. 5b). The maximum Cu-content in SAC_O solder is $0.7 \mathrm{wt}$. \% (Table 2), whereas the predicted lower concentration limit for the solidification through $\eta$ is $0.83 \mathrm{wt}$. $\%$ of $\mathrm{Cu}$. Thus, the solidification through $\beta$-Sn is the only possibility for SAC_O solder. On the other hand, the $\mathrm{Cu}$ variation range for SAC_U solder was found to overlay two different areas of the primary solidification (liquid $+\beta-$-Sn and liquid $+\eta$ ) as illustrated in Fig. 5d. The occurrence of both primary $\beta$-Sn areas and primary $\eta$ particles of the longitudinal morphology in the microstructure of the SAC_U solder (Fig. 2) gives evidence about the solder solidification in two parallel ways (either through $\beta$-Sn or through $\eta$ ). This is possible due to the solder compositional heterogeneity detected by SEM/EDX (Table 2). Partially different ways of solidification, however, did not influence the conformity between the investigated solders regarding the phase occurrence. Almost identical diffraction patterns documented in Figs. 3 and 4 (positions of the peaks are the same, only ratios between the peak heights are partially different) confirm the same types of phases are present in the microstructures of both solders.

As follows from the comparison of the plots illustrated in Figs. 6a and 6b for the SAC_O solder, the calculated $(\mathrm{Cp})$ curve relates closely to the experimental (DSC) curve. All three predicted transitions (3) are also observable on the experimental curve. The differences between calculated and experimental transition temperatures (Table 3 ) are negligible. The transitions at $226.1{ }^{\circ} \mathrm{C}$ and $227.2{ }^{\circ} \mathrm{C}$ are well distinguishable in both the plots (Figs. 6a and 6b). Similarly, good agreement was found between the calculated $(\mathrm{Cp})$ and the experimental (DSC) curves for SAC_U solder, as follows from Figs. 7a and 7b, as well as Table 3. The disappearance of the peak corresponding to the last phase transition (melting of $\eta$ ) in the DSC curve can be explained by a narrow temperature range of the $\eta+$ liquid area at compositions corresponding to SAC_U solder (Fig. 5d). Neither thermodynamic prediction proved any significant thermal effect associated with the $\eta$ melting at $226.5^{\circ} \mathrm{C}$ (see a small step in Fig. 7a).

\begin{tabular}{|c|c|c|c|c|c|c|}
\hline \multirow{2}{*}{ Solder } & \multicolumn{6}{|c|}{ Transition temperatures $\left({ }^{\circ} \mathrm{C}\right)$} \\
\hline & calc. & exp. & calc. & exp. & calc. & exp. \\
\hline SAC_O & 217.5 & 217.6 & 226.1 & 226.1 & 227.3 & 227.2 \\
\hline SAC_U & 217.5 & 217.6 & 226.2 & 226.4 & 226.5 & - \\
\hline
\end{tabular}

\begin{tabular}{|c|c|c|}
\hline \multirow{2}{*}{ Solder } & \multicolumn{2}{|c|}{ Enthalpy of melting $(\mathrm{J} / \mathrm{g})$} \\
\hline & Calculated & Experimental \\
\hline SAC_O & 64.30 & 63.91 \\
\hline SAC_U & 64.80 & 63.55 \\
\hline
\end{tabular}

In Table 4, there is a comparison of the experimentally measured and the calculated enthalpy of melting the investigated solders in the temperature range $215{ }^{\circ} \mathrm{C} \div 228{ }^{\circ} \mathrm{C}$. The measured and the calculated (Thermo-Calc) values of the enthalpy of melting (Table 4) are in a good agreement with each other for the both investigated solders. This confirms the applicability of the phase transitions presented above. 
In this research, the microstructure evolution in the original $\mathrm{Sn}-0.3 \mathrm{Ag}-0.7 \mathrm{Cu}$ solder with that in the solder enriched with $\mathrm{Cu}$ was compared. The results can be useful for determination of the upper concentration limit of $\mathrm{Cu}$ in low-silver SAC solders during wave soldering. The work related to mechanical properties of the investigated solders is in progress.

\section{CONCLUSIONS}

The results obtained from the investigation of the original $\mathrm{Sn}-0.3 \mathrm{Ag}-0.7 \mathrm{Cu}$ solder (SAC_O) and its utilized modification containing more $\mathrm{Cu}$ and $\mathrm{Ag}$ (SAC_U) can be summarized as follows:

1. It was confirmed that the changes in $\mathrm{Cu}$ contents affect both the way of the solder solidification and the microstructure evolution.

2. The original solder was found to solidify through the primary $\beta$-Sn only. It led to the formation of the homogeneous microstructure consisting of regularly distributed $\beta$-Sn areas containing $\eta$ particles of mostly longitudinal morphology and the ternary eutectic $(\beta-S n+$ $\eta+\varepsilon)$.

3. The utilized solder was found to solidify through both $\beta$-Sn and $\eta$. It resulted in the heterogeneous microstructure containing areas of primary $\beta$-Sn, primary $\eta$ particles of the longitudinal morphology, and the ternary eutectic $(\beta-S n+\eta+\varepsilon)$.

4. The predicted $\mathrm{Cp}$ curves show proportionality to the experimental DSC curves for both the solders.

5. Melting temperatures 227.6 and $226.6{ }^{\circ} \mathrm{C}$ were experimentally determined for the SAC_O and SAC_U solders, respectively.

6. The experimentally determined values of enthalpy of melting 63.91 and $63.55 \mathrm{~J} / \mathrm{g}$ were determined for the SAC_O and SAC_U solders, respectively.

7. Good agreement between the predicted data (calculated by Thermo-Calc) and the experimental results were attained in this research.

\section{Acknowledgement}

The authors would like to thank for the financial support provided for the project of Centre for Development and Application of Progressive Diagnostic Methods in the Process of Metallic and Non-metallic Material's Processing within the Program for Research and Development, ITMS: 26220120048, co-financed by the European Foundation for Regional Development. This study was also funded by the VEGA Grant Agency under the contract No. 1/0151/17 and the APVV Grant Agency under the APVV-15-0049 contract.

\section{References:}

1. M. ABTEW, G. SELVADURAY. 2000. Mater. Sci. Eng., R 27, pp. 95-141.

2. http://ec.europa.eu/environment/waste/rohs_eee/legis_en.htm. Accessed 12 January 2015.

3. S-K. SEO, S. K. KANG, D-Y. SHIH, H. M. LEE. 2009. Microelectron. Reliab. 49, pp. 288-295.

4. J. SHEN, Y. LIU, Y. HAN, H. GAO, CH. WEI, Y. YANG. 2006. Trans. Nonferrous Met. Soc. China 16, pp. 59-64.

5. K.S. KIM, S.H. HUH, K. SUGANUMA. 2002. Mater. Sci. Eng., A 333, pp. 106-114.

6. D. SUH, D.W. KIM, P. LIU, H. KIM, J.A. WENINGER, CH.M. KUMAR, A. PRASAD, B.W. GRIMSLEY, H.B. TEJADA. 2007. Mater. Sci. Eng., A 460-461, pp. 595-603.

7. K. KANLAYASIRI, T. ARIGA. 2010. J. Alloys Compd. 504, L5-L9.

8. K. KANLAYASIRI, M. MONGKOLWONGROJN, T. ARIGA, J. 2009. Alloys Compd. 485, pp. 225-230.

9. N. MOOKAM, K. KANLAYASIRI, J. 2011. Alloys Compd. 509, pp. 6276-6279. 
10. K.-W. MOON, W. J. BOETTINGER, U. R. KATtNER, F. S. BIANCANIELlO, C. A. HANDWERKER, J. 2000. Electron. Mater. 29, pp. 1122-1236.

11. I. OHNUMA, M. MIYASHITA, K. ANZAI, X.J. LIU, H. OHTANI, R. KINUMA, K. ISHIDA, J. 2000. Electron. Mater., 29(10), pp. 1137-1144.

12. M.E. LOOMANS, M.E. 2000. Fine, Metall. Mater. Trans., A 31A, pp. 1155-1162.

13. J. SOPOUŠEK, M. PALCUT, E. HODÚLOVÁ, J. JANOVEC, J. 2010. Electron. Mater. 39, pp. 312-317.

14. A. DINSDALE, A. WATSON, A. KROUPA, J. VRESTAL, A. ZEMANOVA, J. VIZDAL 2008. COST Action 531 - Atlas of Phase Diagrams for Lead-Free Soldering, Volume 1, (COST office), pp. 175-181.

15. T. LAURILA, V. VUORINEN, J.K. KIVILAHTI. 2005. Mater. Sci. Eng., R 49, pp. 1-60.

16. X. SANG, K. DU, H. YE, J. 2009. Alloys Compd. 469, pp.129-136.

17. M. YANG, M. LI, L. WANG, Y. FU, J. KIM, L. WENIG. 2011. Mater. Lett. 65, pp. 1506-1509.

18. H. - Y. HSIAO, C. - C. HU, M. - Y. GUO, C. CHEN, K. N. TU. 2011. Scr. Mater. 65 pp. 907910.

19. J.W. YOON, S-B JUNG, J. 2008. Alloys Compd. 458, pp. 200-207.

20. K. NOGITA. 2010. Intermetallics 18, pp. 145-149.

21. K. NOGITA, C.M. GOURLAY, S.D. MCDONALD, Y.Q. WU, J. READ, Q.F. GU. 2011. Scr. Mater. 65, pp. 922-925.

22. S. CHADA, R. A. FOURNELLE, W. LAUB, D. SHANGGUAN, J. 2000. Electron. Mater., 29(10), pp. 1214-1221.

23. N. SAUNDERS, A.P. MIODOWNIK. 1998. Calculation of Phase Diagrams, A Comprehensive Guide. Elsevier Science Ltd., pp. 44-57.

\section{ORCID:}

Marián Drienovský

Pavol Priputen

Marcela Pekarčíková
0000-0002-6493-6129

$0000-0002-6259-5711$

0000-0002-4300-6109 
